\title{
EDITORIAL 24.3
}

Finalmente, chegamos à terceira edição do nosso periódico em 2012. Na edição atual, contamos com quatro artigos internacionais e artigos nacionais de distintas procedências. Começamos a edição atual de Fractal: Revista de Psicologia, com o artigo "Spinoza et la question éthico-sociale du désir: études comparatives avec Epicure-Lucrece et Machiavel" de autoria de Laurent Bove da Université de Picardie Julie Verne, na França. Contamos com a tradução do artigo, feita por Leon Neto, da Universidade Federal de Santa Catarina. No artigo, Bove analisa a filosofia de Spinoza ao se debruçar sobre o tema do desejo, reconhecendo a importância das tradições filosóficas citadas no título do estudo. A seguir, temos o artigo "Professionnalité des ensignants: vérs un définition de collectif à partir d'une recherche au Lycée autogéré de Paris (LAP)" de autoria de Maria Papantoniou da Université de Bordeaux, na França. No artigo, Papantoniou analisa os impactos de uma experiência no Liceu autogerido de Paris, centrando-se nas relações entre os alunos e nas relações com outros sujeitos, priorizando uma discussão sobre o tema da violência. O próximo artigo se intitula "Personajes: notas sobre Deleuze y la novela modernista", de autoria de Juan Carlos Gorlier da Universidade de Buenos Aires, na Argentina. No artigo, Gorlier analisa distintos status de personagens literários, dialogando com a filosofia de Gilles Deleuze, parte da obra de Friedrich Nietzsche e a literatura de Virginia Wolf, centrando-se na impessoalidade de alguns personagens e, mesmo, em sua ausência. O quarto e último artigo internacional de nosso presente volume se intitula "Straight to the point: how people encode linear discontinuations", de autoria de Rodrigo Mora, Alejandro Lobos e Agustín Ibáñez, da Universidade Diego Portales, do Chile. No artigo, Mora, com o auxílio de profissionais do campo da Psicologia, indica as características de uma pesquisa feita com 50 pessoas no Chile a respeito da caracterização de descontinuidades espaciais, o que se concebe cotidianamente em nossas acepções do espaço.

Na seção dedicada a artigos nacionais, contamos com as seguintes contribuições: "Expressão e conhecimento: a linguagem na Fenomenologia da Percepção" de Danilo Saretta Veríssimo, da Faculdade de Ciências e Letras de Assis, pertencente a Universidade Estadual Paulista Júlio de Mesquita Filho ( UNESPAssis). No artigo, Veríssimo se dedica a compreender a concepção de linguagem que Merleau-Ponty formula ao criticar a tendência intelectualista em estudos da linguagem e o projeto de Jean Piaget em relação ao mesmo tema. A seguir, temos o artigo "Representações sociais de estudantes universitários sobre cotas na Universidade", de autoria de Paula Bacellar e Silva e Patrícia da Silva, da Universidade Federal da Bahia. No artigo, as autoras problematizam as representações de estudantes da Universidade Federal da Bahia a respeito da inserção de alunos cotistas nas Universidades Federais, fazendo uso de pesquisa realizada com grupo de estudantes em diferentes momentos de suas formações. $\mathrm{O}$ artigo seguinte se intitula "Representações de mães adolescentes: aspectos intergeracionais na relação mãe-criança", de autoria de Stela Cabral e Daniela Levandowski, da Universidade do Vale do Rio dos Sinos e da Fundação Universidade Federal de Ciências da Saúde de Porto Alegre, respectivamente. No artigo, as autoras se dedicam

Fractal, Rev. Psicol., v. 24 - n. 3, p. 439-442, Set./Dez. 2012 
a problematizar, por intermédio de pesquisa realizada com mães adolescentes, a influência da relação destas mães com suas próprias mães na natureza do vínculo estabelecido com seus filhos, subsidiando-se, em parte, no campo da psicanálise para efetivar suas discussões teóricas e metodológicas. O artigo seguinte se intitula "Desigualdade racial, racismo e seus efeitos", de autoria de Maria Helena Zamora, da Pontifícia Universidade Católica do Rio de Janeiro. No artigo, Zamora se dedica a discutir as noções de raça, racialismo e racismo, subsidiando-se na filosofia de Michel Foucault e com grande preocupação com o entendimento de algumas pesquisas realizadas a partir do campo da Psicologia em nosso país sobre o tema em análise. O artigo seguinte se intitula "Gilles Deleuze, clínico da atividade filosófica: paradoxo do filósofo trabalhador" de autoria de Jésio Zamboni e Maria Elizabeth Barros de Barros, da Universidade Federal do Espírito Santo. No artigo, os autores se debruçam sobre o pensamento de Gilles Deleuze, reconhecendo sua tarefa e sua militância como operário dos conceitos, sugerindo conexões com o próprio trabalho docente. O próximo artigo se intitula "Biopoder e UPPs: alteridade na experiência de policiamento permanente em comunidades cariocas", de autoria de Thiago Benedito Livramento Melício, Janaina Rodrigues Geraldini e Pedro Paulo Gastalho de Bicalho, da Universidade Federal do Rio de Janeiro. No artigo, os autores apresentam as reflexões e problematizações articuladas a partir de estudos exploratórios em duas comunidades do Rio de Janeiro em que se estabeleceram Unidades de Polícias Pacificadoras, relacionando a complexidade do cenário em análise com a filosofia de Michel Foucault. $\mathrm{O}$ artigo seguinte se intitula "Assim falava Barbie: uma boneca para todos e para ninguém", de autoria de Michelle Brugnera Cruz Cechin e Thaise da Silva, do Instituto Educacional do Rio Grande do Sul e da Universidade Federal do Rio Grande do Sul. No artigo, as autoras se reportam aos estudos culturais pós-estruturalistas para sugerirem uma compreensão da boneca Barbie como um artefato cultural, incidindo sobre políticas de gênero e de diversidade cultural em diferentes sociedades. O artigo traz importantes contribuições para estudos sobre brinquedos na contemporaneidade.

O próximo artigo se intitula "Crítica ao postulado positivista em Psicologia: de Heidegger a Foucault", de autoria de Rômulo Marques dos Santos Ballestê e Ricardo de Barros Cabral, do Instituto Brasileiro de Medicina e Reabilitação e da Universidade Federal do Rio de Janeiro, respectivamente. No artigo, os autores se reportam ao pensamento de Michel Foucault e de Martin Heidegger a fim de estabelecerem um diagnóstico da chamada ciência da psicologia, defendendo que a discussão sobre a objetivação do homem e sua identificação com o fato biológico deve ser confrontada a uma remissão ao tema da ética. Temos uma seção dedicada a resenhas de livros. A primeira resenha se intitula "Os laços feitos entre a linguagem e a subjetividade", de autoria de Leonardo Pinto de Almeida sobre o livro Nudos del linguaje: cuerpo, escritura, voz de J. C. Gorlier e editado por EUDEM em 2011. A próxima resenha é sobre o livro Pesquisar na diferença: um abecedário, escrito por Tania Galli Fonseca e outros, editado pela Editora Sulina em 2012. A autora da resenha é a professora Marcia Oliveira Moraes, que intitulou sua contribuição de "O pesquisar em ação". Temos, ainda, um relato de experiência profissional intitulado "Memórias e narrativas tecidas em 
uma experiência extensionista", de autoria de Eduardo Antonio de Pontes Costa e Maria de Fátima Pereira Alberto, da Universidade Federal da Paraíba. O relato se baseia em uma profícua experiência extensionista na Universidade Federal da Paraíba e se sustenta em discussões empreendidas por Paulo Freire e por Walter Benjamin, em seus distintos campos teóricos. Com as contribuições tornadas públicas em nosso atual volume, encerramos as atividades de 2012, reiterando o convite aos nossos leitores e colaboradores para que compartilhem as discussões formuladas pelos autores dos artigos e resenhas que compõem o volume 24.3 de Fractal: Revista de Psicologia. Excelente leitura!

\section{Marcelo Santana Ferreira}

Editor de Fractal: Revista de Psicologia. 
